Sipping Fuel and Saving Lives: Increasing Fuel Economy Without Sacrificing Safety

A Report Informed by an October 3, 2006, Experts Workshop on Simultaneously Improving Vehicle Safety and Fuel Economy Through Improvements in Vehicle Design and Materials 


\section{Sipping Fuel and Saving Lives: Increasing Fuel Economy Without Sacrificing Safety}

A Report Informed by an October 3, 2006, Experts Workshop on Simultaneously Improving Vehicle Safety and Fuel Economy Through Improvements in Vehicle Design and Materials

\section{ičct}

Prepared for The International Council on Clean Transportation

by

Deborah Gordon

Transportation Policy Consultant

David L. Greene

Fuel Economy Policy Expert

Marc H. Ross

University of Michigan

Department of Physics, Emeritus Professor

Tom P. Wenzel

Lawrence Berkeley National Laboratory 
The International Council on Clean Transportation (ICCT) seeks to dramatically reduce conventional pollutant and greenhouse gas emissions from personal, public, and goods transportation in order to improve air quality and human health, and mitigate climate change. The Council is made up of the leading regulators and experts from around the world that participate as individuals based on their experience with air quality and transportation issues. The ICCT promotes best practices and comprehensive solutions to improve vehicle emissions and efficiency, increase fuel quality and sustainability of alternative fuels, reduce pollution from the in-use fleet, and curtail emission from international goods movement.

The William and Flora Hewlett Foundation, which provided support for the report, makes grants to address the most serious social and environmental problems facing society, where risk capital, responsibly invested, may make a difference over time. The Foundation places a high value on sustaining and improving institutions that make positive contributions to society. 


\section{Table of Contents}

1 Executive Summary

2 Building Higher-Fuel-Economy, Safer Vehicles

3 Introduction: Slow Progress on Vehicle Fuel Economy and Safety

5 The Potential for Improved Fuel Economy and Safety

5 Why Vehicle Fuel Economy and Safety Improvements Matter

Climate Change and Air Pollution

Oil Dependence and Economic Disruption

Oil Imports, National Security, and Trade Deficits

Injury and Fatality

7 Safety and Fuel Economy: New Realities

Reality \#1: Fuel economy standards have not stopped Americans from buying large auto

Reality \#2: Lightweight, fuel-efficient vehicles can be built for safety

Reality \#3: Some SUVs and pickups pose safety risks for their drivers and others on the road

Reality \#4: Fuel economy improvements have not occurred through market forces

11 Concepts and Technologies Underpinning Safety and Fuel Economy

Fuel Economy Technologies

Safety Technologies

Vehicle Weight

Technology Costs

15 Research Findings on Vehicle Fuel Economy and Safety

15 Challenges and Barriers

Safety Testing Limitations

Model Limitations

Safety Testing Limitations

Consumer Information Limitations

16 Opportunities for Moving Forward - Sipping Fuel and Saving Lives

18 Appendix A: List of Expert Attendees and Affiliations

21 Appendix B: Summary of Workshop Papers and PowerPoint Presentations

24 References 


\section{Executive Summary}

The public, automakers, and policymakers have long worried about trade-offs between increased fuel economy in motor vehicles and reduced safety. The conclusion of a broad group of experts on safety and fuel economy in the auto sector is that no trade-off is required. There are a wide variety of technologies and approaches available to advance vehicle fuel economy that have no effect on vehicle safety. Conversely, there are many technologies and approaches available to advance vehicle safety that are not detrimental to vehicle fuel economy.

Congress is considering new policies to increase the fuel economy of new automobiles in order to reduce oil dependence and reduce greenhouse gas emissions. The findings reported here offer reassurance on an important dimension of that work: It is possible to significantly increase the fuel economy of motor vehicles without compromising their safety.
Automobiles on the road today demonstrate that higher fuel economy and greater safety can co-exist. Some of the safest vehicles have higher fuel economy, while some of the least safe vehicles driven today - heavy, large trucks and SUVs — have the lowest fuel economy (see graph).

At an October 3, 2006 workshop, leading researchers from national laboratories, academia, auto manufacturers, insurance research industry, consumer and environmental groups, material supply industries, and the federal government agreed that vehicles could be designed to simultaneously improve safety and fuel economy. The real question is not whether we can realize this goal, but the best path to get there.

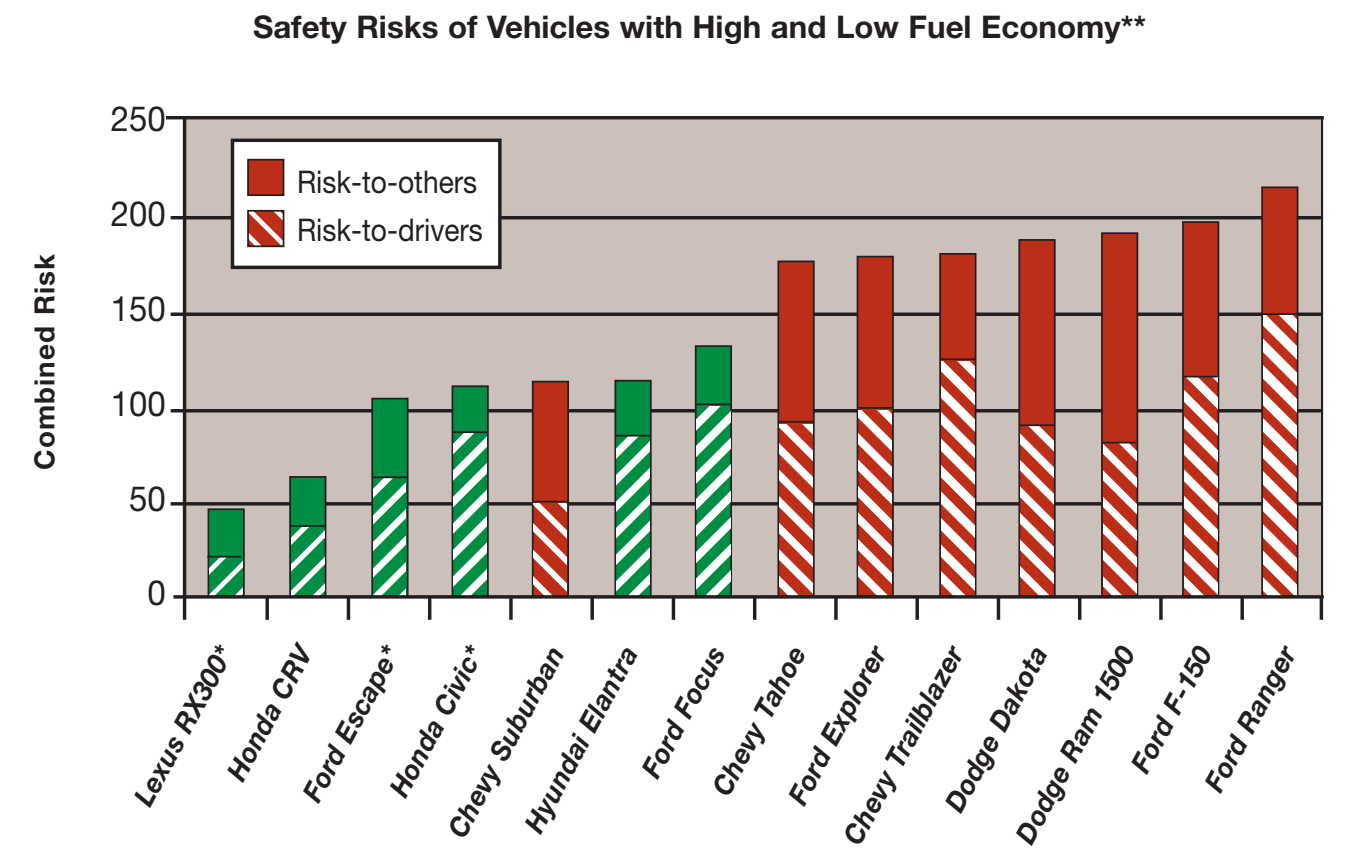

Source: Wenzel and Ross 2006

${ }^{*}$ Hybrid model available

** Combined risk includes the risks to own driver and to other drivers

Note: All green cross hatch bars (////) represent fuel efficient vehicle models; All red cross hatch bars (III) represent inefficient vehicle models. 
The experts' studies reveal important new conclusions about fuel economy and safety, including:

- Vehicle fuel economy can be increased without affecting safety, and vice versa.

- Reducing the weight and height of the heaviest SUVs and pickup trucks will simultaneously increase both their fuel economy and overall safety.

- Advanced materials can decouple size from mass, creating important new possibilities for increasing both fuel economy and safety without compromising functionality.

\section{Building Higher-Fuel-Economy, Safer Vehicles}

The key to delivering both safety and fuel economy lies in vehicle design. Poor design decisions and bad technology choices undermine vehicle safety as well as fuel economy. The main factors influencing vehicle safety include crashworthiness, crash avoidance, and built-in aggressivity. Crashworthiness considers the ability of a vehicle to protect its occupants in the event of a crash. Crash avoidance is the ability of a vehicle, through manual and automated handling and braking, to avoid a serious crash altogether. Aggressivity is determined by designs that make a vehicle incompatible and more dangerous to others it comes into contact with.

Technologies exist today that can improve light-duty vehicle fuel economy by up to 50 percent over the next 10 years without reducing the size of vehicles. With gasoline prices in the vicinity of $\$ 3.00$ per gallon, fuel savings alone would pay for these improvements. If these technologies were carefully applied, in accordance with safety and environmental standards, fuel economy could be increased dramatically with no impact on safety. In addition, there are technologies available to improve vehicle safety that would have little or no effect on fuel economy (see examples in table).

\section{Some Technology Options for Increasing Fuel Economy and/or Safety}

\begin{tabular}{|c|c|c|}
\hline Available Vehicle Technologies & $\begin{array}{l}\text { Relative Fuel Economy } \\
\text { Gain }\end{array}$ & $\begin{array}{l}\text { Relative } \\
\text { Safety Gain }\end{array}$ \\
\hline $\begin{array}{l}\text { Uni-body Construction/ Advanced High-Strength } \\
\text { \& Aluminum }\end{array}$ & +++ & + \\
\hline Low-Friction 6-Cylinder Engine & ++ & no effect \\
\hline Direct Injection Engine & +++ & no effect \\
\hline Integrated Starter-Generator & ++ & no effect \\
\hline 6-Speed Automatic Transmission & + & no effect \\
\hline $\begin{array}{l}\text { Lower Rolling Resistance Tires, improved } \\
\text { aerodynamics \& accessories }\end{array}$ & + & no effect \\
\hline Effective Electronic Seat Belt Reminders & no effect & +++ \\
\hline Stronger Roof and Body Structure & no effect ${ }^{\star}$ & +++ \\
\hline Electronic Stability Control & no effect ${ }^{*}$ & ++ \\
\hline Rollover-Activated Belt Pretensioners & no effect & ++ \\
\hline Window Curtain Air Bags & no effect ${ }^{\star}$ & ++ \\
\hline Lower Aluminum Bumper Beams & no effect & + \\
\hline Automated Event Accident Recorders & no effect* & ++ \\
\hline
\end{tabular}

Sources: UCS 2006; NRC 2002; German 2006; Authors' estimations. "+” represent degrees of gain for each technology, +++ with the greatest gains. ${ }^{*}$ The additional weight of safety technologies is small and only affects fuel economy on the margin. 
Many experts at the workshop agreed that strategic weight reduction (that is, using new lightweight materials to reduce weight while holding vehicle size constant and reducing the weight of the heaviest trucks and SUVs to make them less aggressive) could be achieved while maintaining, or even improving, safety. Although some workshop participants disagreed with this conclusion, all participants did agree that there is ample opportunity to improve fuel economy without reducing vehicle crashworthiness and occupant safety. Automakers have not consistently optimized their vehicle designs, and there are many design and behavioral variables that can affect safety. Nevertheless, some automakers-VW and Honda, for example-are designing their lighter vehicles to be as safe as heavier vehicles and with higher fuel economy. Several manufacturers with strong safety records, especially for the European market, are producing a fleet of lightweight, safe, high-fuel-economy cars.

Henry Ford himself likely would have agreed that low vehicle mass is not inherently detrimental to safety. $\mathrm{He}$ claimed in his 1922 memoir that he would have made his Model $\mathrm{T}$ lighter if he had only known how.

\section{Introduction: Slow Progress on Vehicle Fuel Economy and Safety}

Henry Ford felt, when it came to automobiles, strong and light took the prize. Ford stressed, "For some clumsy reason we have come to confuse strength with weight. Weight may be desirable in a steamroller, but nowhere else. The old ox-cart weighed a ton-and it had so much weight that it was weak! The most beautiful things in the world are those from which all excess weight has been eliminated. The car that I designed was lighter than any car that had yet been made. It would have been lighter if I had known how to make it so" (Ford 1922).

The Model T weighed in at 1,200 pounds and was said to cover an estimated 20 miles on a gallon of gasoline. Henry Ford probably could not have envisioned that vehicles with curb weights of 3 tons, such as the F-350 pickup, would routinely roll off his assembly lines in
2007. Many of these trucks are so heavy that they have been exempt from having their fuel economy measured and reported, but they likely travel less on a gallon of gasoline that the century-older Model T. ${ }^{1}$ In spite of their excessive weight, the largest SUVs and trucks are some of the least safe autos on the road today.

Automobiles have changed over the years-at least somewhat. In 1975, a typical American passenger car drove 13.5 miles per gallon, weighed 4,058 pounds, had a 136-horsepower engine, and featured an interior volume of 110 cubic feet. Cars were the norm, with light trucks comprising fewer than one in five lightduty vehicles sold-predominantly for agriculture, delivery, and other business purposes. The typical light truck got 11.6 miles per gallon, weighed 4,072 pounds, and had a 142-horsepower engine (Heavenrich 2006).

Thirty years later, the average 2006 model year lightduty passenger vehicle weighs in at 4,142 poundsonly 2 percent more than 1975 . And the average vehicle fuel economy is now 21 miles per gallon, 60 percent higher than 1975. This increase has been achieved despite the fact that light trucks now claim 50 percent of the new light-duty vehicle fleet, and passenger car horsepower increased 46 percent, while light truck horsepower was up 68 percent (Heavenrich 2006).

Automakers have succeeded in increasing vehicle fuel economy and safety. Fatality rates (deaths per capita) from auto accidents have fallen over the past four decades by 43 percent, while injury rates have dropped on the order of 35 percent (NHTSA 2006). And even as new vehicles became more and more powerful, equipped with accessories that consumed increasing amounts of fuel, the average new vehicle fleet-wide fuel economy stood steady at 21 miles per gallon.

In reality, unfortunately, less progress has been made than appears to be the case. The entire 60 percent rise in new vehicle fuel economy took place immediately after Corporate Average Fuel Economy (CAFE) standards were implemented. Since 1982 the fuel economy of new autos has not essentially changed (Heavenrich 2006). The driver fatality rate per million vehicles for

${ }^{1}$ Current CAFE standards exempt vehicles over 8,500 pounds GVWR (gross vehicle weight rating, or total carrying capacity); many of today's trucks and SUVs are not regulated in terms of their fuel economy. 


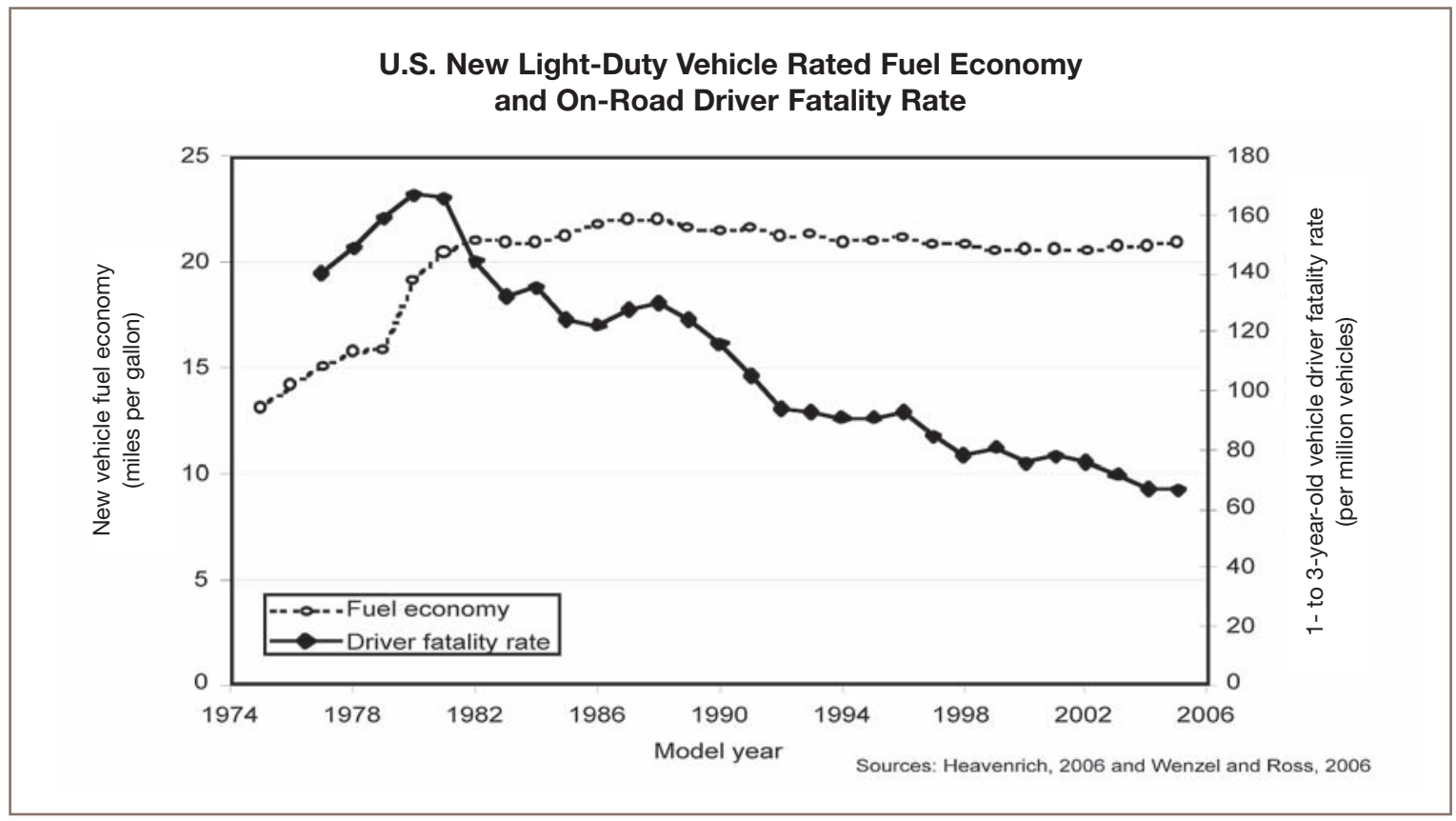

new, one- to three-year-old vehicles increased shortly after CAFE standards were adopted, but has since declined by more than 50 percent (see figure above). Despite this progress in new vehicle safety in the U.S., the European Union, Canada, and Japan have seen even more dramatic reductions in fatality rates (see figure below). Fewer light-duty trucks, more stringent seatbelt and drunk driving laws, tighter driver licensing requirements, and accelerated use of new safety technologies in other countries might help explain why fatality rates have decreased more rapidly in other developed nations.

\section{International Motor Vehicle Fatality Rates*, per million vehicles and total}

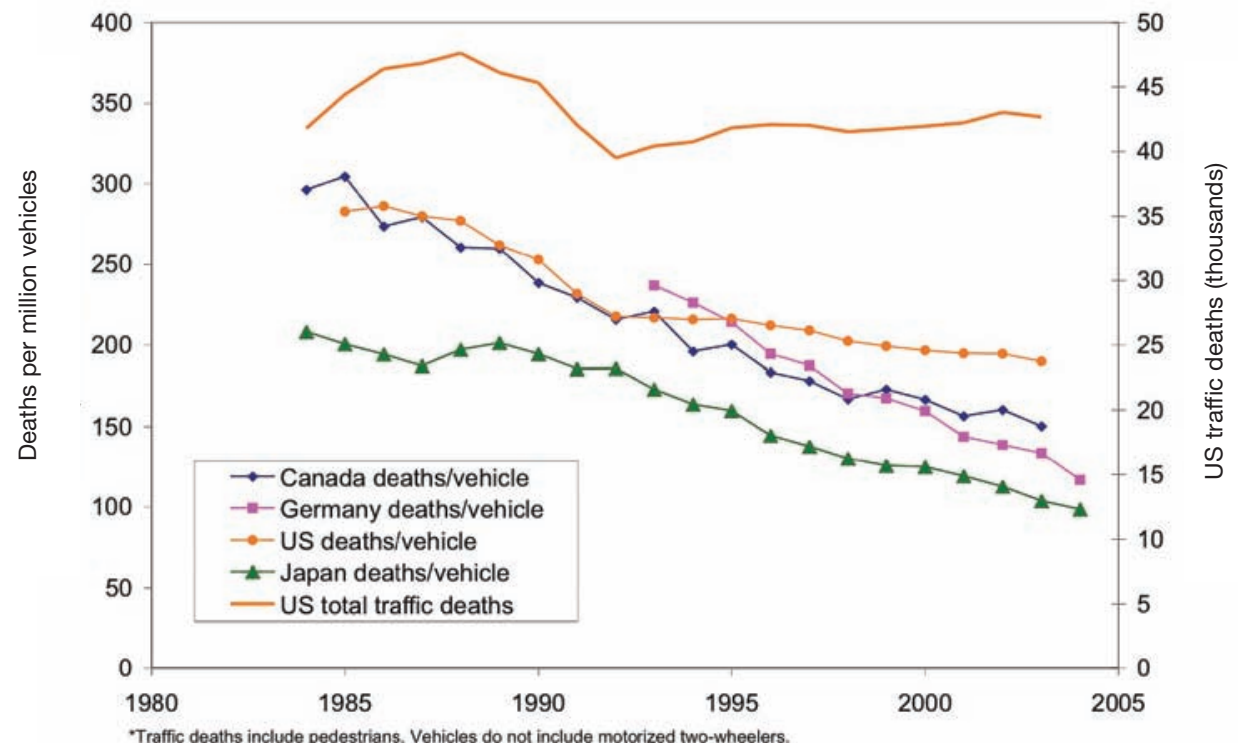

Source: Wenzel and Ross 2006 


\section{The Potential for Improved Fuel Economy and Safety}

Improved fuel economy and safety are available in select models. The fuel economies of the "best in their class" are on the order of 15-20 percent higher than the "worst in class." For example, a similarly sized and equipped Hyundai Elantra (28 combined mpg) consumes 18 percent less fuel than the Mazda $6(23 \mathrm{mpg}$ ). For any given model, more-powerful, automatic versions have on the order of 20 percent greater fuel consumption than their less-powerful, manual configurations-VW Passat delivers $24 \mathrm{mpg}$ for a manual, 4cylinder, 2-liter engine versus $19 \mathrm{mpg}$ for an automatic, 6-cylinder, 3.6-liter engine. Hybrid models deliver varying improvements in fuel savings, depending on the type of hybridization and the specific design decisions affecting the allocation among fuel economy, weight, power, and performance. Compare today's hybrids to their conventional counterparts: the Ford Escape (19 mpg) versus the Ford Escape Hybrid (30 mpg), a 37 percent fuel savings; Honda Civic DX (29 mpg) to the Civic Hybrid (42 mpg), a 31 percent fuel savings; and the Toyota Matrix (27 mpg) to the Toyota Prius (46 mpg), a 41 percent fuel savings ${ }^{2}$ (US EPA 2007).

Many technologies are available for even further fuel economy improvement-gasoline direct injection engines with lean burn and turbocharging, variable valve timing and lift control, engine idle off, cylinder deactivation, camless valve activation, electric power steering, electric water pumps, lightweight construction, improved aerodynamic design, lower-rollingresistance tires, and a growing number of other engine technology and transmission improvements. The National Academy of Sciences (NAS) reported in 2002 that it was feasible for automakers to bring their national fleet-wide average fuel economy up to at least 37.1 miles per gallon (NRC 2002). Other researchers claim higher potential gains-to nearly 42 miles per gallon fleet-wide (UCS 2006).

The stunning potential for enhanced vehicle safety is no different. Many safety technologies and lightweight materials are available—electronic stability control, stronger roofs, pillars to improve crashworthiness, com- patible car and truck front-end heights, side curtain airbags, strong lightweight materials, and improved seatbelts are some of the most promising technologies. In addition, more stringent seat belt and drunk driving laws and their enforcement, and tighter driver licensing requirements, have already led to significant declines in on-road fatalities, and more can be done.

This report is informed by a workshop for automotive analysts on how fuel economy can be advanced without sacrificing vehicle safety. The analysts' overarching conclusion is that no trade-off is required between vehicle safety and fuel economy; these important goals can be optimized simultaneously.

In this document we describe the benefits of improving vehicle fuel economy and safety; clarify some of the common misunderstandings about the complex relationship between fuel economy and safety; introduce the design concepts and technologies that exist today to build safer and higher-fuel-economy autos; discuss the newest research from the workshop that informs this report; identify a few of the challenges and barriers that safer, higher-fuel-economy vehicles face; and conclude with opportunities for moving forward.

\section{Why Vehicle Fuel Economy and Safety Improvements Matter}

It is becoming increasingly important to package fuel economy and safety together in the vehicles we drive. There are many reasons for this. Improved vehicle fuel economy and safety address many problems at onceclimate change, air pollution, oil dependence, oil imports, national security, trade deficits, and the incidence and severity of traffic injuries and fatalities are directly influenced by the vehicles that manufacturers design and consumers purchase.

\section{Climate Change and Air Pollution}

The increase in global temperatures that has long been predicted to alter the climate has already begun to affect many of Earth's life systems. Warming over the 20th century has led to shrinking glaciers, thawing permafrost, shifts in plant and animal habitats, and the proliferation of insects (IPCC 2001). The U.S. has

2 EPA recently revised the methods for estimating vehicle fuel economy to better represent current driving styles and conditions. The new methods apply to model year 2008 and later vehicles; see www.fueleconomy.gov for more details. 


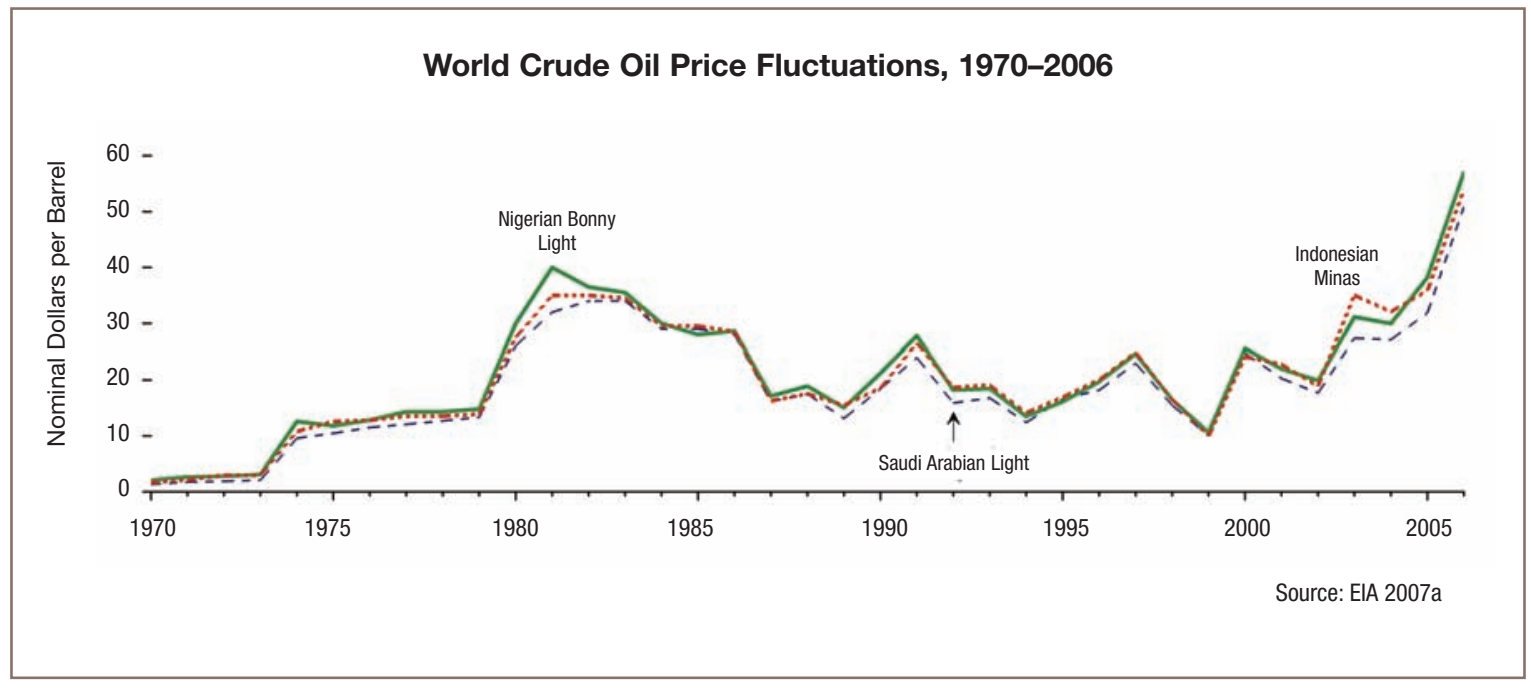

done little to rein in the irreversible damage that is being done-especially when it comes to U.S.-made automobiles. The link between autos and climate change is a direct one. Every gallon of gasoline burned releases approximately 20 pounds of carbon dioxide. The U.S. emits more carbon dioxide (the principal greenhouse gas) than Japan, Canada, Australia, and all of Western Europe combined (EIA 2006). Even on a per-capita basis, U.S. carbon dioxide emissions are more than double those in Japan and Western European nations and greater than Canada and Australia.

Diesel fuel has long presented a confounding concern when it comes to delivering greater fuel economy while protecting public health. Diesel engines are inherently more fuel-efficient than those running on gasoline. Yet the South Coast Air Quality Management District found diesel exhaust to be carcinogenic in a landmark study (SCAQMD 2000). New, cleaner ultra-low-sulfur diesel is now on the market. Cleaner diesel fuels should produce lower particulate emissions as well as allow the use of improved exhaust treatment devices to further reduce air pollutant emissions. Cleaner diesel may make it more viable to use a diesel fuel strategy to bring about fuel economy improvements in the future.

\section{Oil Dependence and Economic Disruption}

While our entire economy depends to a certain extent on oil, transportation is the sector most affected. Gasoline used by motor vehicles accounts for 70 percent of all U.S. oil consumption (EIA 2007a).
Oil prices have fluctuated dramatically over the past 35 years (see figure above). These price swings are disruptive, and they make it very difficult for consumers to make rational vehicle purchase decisions. Private oil companies have little control over market prices. OPEC has more influence on prices through their long-run decisions about production capacity and their short-run decisions about production quotas. There are also uncontrollable factors influencing oil supply and demand, from aging refineries to increasing fuel use by China and elsewhere to debilitating hurricanes. A terrorist attack on Saudi oil infrastructure could send a barrel of crude past $\$ 100$; a financial-market crash could push it below $\$ 10$. Perhaps the only guarantee is that the price of oil is unlikely to remain stable in the future, making it difficult for the market to meet fuel economy goals without guidance from public policy.

\section{Oil Imports, National Security, and Trade Deficits}

The world's petroleum markets, once under the control of private corporations in the U.S. and Europe, are now owned and run by new corporate structures. Through the 1960s, private, Western corporations had access to 85 percent of the world's oil reserves. Today, most of the world's oil and gas is restricted or entirely cordoned off from the West. Instead, oil nations control over two-thirds of the world's oil. (EIA 2007 b). Oil imports supply 60 percent of U.S. demands-with nearly one-half of these imports from OPEC nations. 
National security is, in part, influenced by oil flows. And these are increasingly influenced by political conditions.

Not only is the U.S. dependent on these oil-rich nations, trillions of American dollars are handed over each decade to totalitarian regimes in exchange for petroleum. A U.S. trade deficit on the order of $\$ 300$ billion a year is due to oil imports (Jackson 2006). Moreover, as much as an estimated $\$ 60$ billion a year is spent on military defense of oil supplies in the Middle East (Davis 2006). These sums are expected to rise.

\section{Injury and Fatality}

Accidents, injuries, and fatalities are still numerous despite technological advances, regulation, and public outreach. Over 43,000 people are killed and 2.7 million are injured a year on roads and in motor vehicles (NHTSA 2006). Beyond the pain and suffering caused by traffic accidents, this is a costly situation. Medical expenses, lost wages, sick leave, insurance outlays, and a host of other costs can follow a serious injury or death. Not only do we have to make vehicles safer for their own occupants, we must make vehicles more compatible with one another to address safety concerns for all vehicles traveling on the road.

\section{Safety and Fuel Economy: New Realities}

The inherent relationship between vehicle safety and fuel economy has long been the subject of discussion. The many technologies available to improve vehicle fuel economy (particularly those that do not involve weight reduction) have no impact on vehicle safety. Those approaches that strategically reduce vehicle weight (using new lightweight materials to reduce weight while holding vehicle size constant and reducing the weight of the heaviest trucks and SUVs to make them less aggressive) also improve fuel economy while maintaining, and perhaps even improving, vehicle safety.

Poor vehicle design decisions, including those that involve badly-executed weight reduction, could compromise safety. However, such a strategy is not required to meet fuel economy goals. Still researchers debate the safety versus vehicle weight issue. We present the research here because it is part of the debate, not because it necessary to realizing fuel economy gains.
The potential to improve the fuel economy of lightduty vehicles while also improving traffic safety is debated because of the claim that lighter vehicles are, and will forever remain, more dangerous for their occupants. The critical issue is whether these historical tendencies are intrinsic, or whether they continue to change over time with new designs, testing, and sound regulations. The reality is that these relationships are not intrinsic to motor vehicles. Rather, the linkages among fuel economy, vehicle size, weight, and safety are manageable and are more a function of smart vehicle design than any other single factor (Wenzel and Ross 2006).

Two National Highway Traffic Safety Administration (NHTSA) studies examined the effects of hypothetical changes in vehicle weight upon fatalities (Kahane 1997, 2003). These studies did not distinguish between weight and size, claiming heavier vehicles are intrinsically safer than light vehicles. They also did not adequately control for the likely correlation between unobserved driver attributes (inattentiveness and aggressiveness) and vehicle attributes. A statistical analysis of the correlation between fuel economy and traffic fatalities covering the period from 1966 to 2002 have either produced inconclusive results using statelevel data (Noland 2004), or have conclusively demonstrated that there was no such correlation at the national level (Ahmad and Greene 2005).

A more recent study by Dynamic Research, Inc. (DRI), which isolates changes in vehicle size from changes in vehicle weight, found that when vehicle size is held constant, increases in weight increase fatalities, contradicting the Kahane studies' conclusions (Van Auken and Zellner 2005a). The DRI study (sponsored by Honda) further indicates that vehicles would be safer if they were made lighter but retained their overall dimensions. A more recent study by Wenzel and Ross (2006) found that on-road safety varies substantially, even for models of similar size and weight, suggesting that vehicle design plays a large role in safety.

Kahane later acknowledged that his 2003 study "did not claim that mass per se is the specific factor that increases or decreases fatality risk"; rather, "in this type of analysis, 'vehicle mass' incorporates not only the effects of mass per se but also the effects of many 
other size attributes that are historically... related to mass, such as wheelbase, track width and structural integrity." Changes in the relationship between vehicle weight and size, such as using new, stronger materials to reduce weight while maintaining size, or "increased use of advanced restraint systems or sophisticated crash avoidance safety devices, could have a noticeable impact on the historical relationship between vehicle mass and fatality risk in future vehicle fleets" (Kahane 2004).

The DRI and Wenzel and Ross results on the different effects of weight and size on safety are also consistent with results reported by O'Neill, Evans, Kebschull, and many others. O'Neill, Joksch, and Haddon reported in 1974 that increases in vehicle size were "primarily protective," whereas increases in vehicle weight was "primarily hostile" (O'Neill, Joksch, and Haddon 1974). O'Neill later added that "cars with added crush distance can provide increased protection not only to their occupants but to the occupants of other vehicles with which they may collide. Weight, on the other hand, protects some occupants but often at the expense of others" (O'Neill 1998). Evans reported empirical equations for fatality risk in two-vehicle, head-on collisions that indicate that weight reduction tends to have a self-canceling effect on the total driver fatality risk (Evans 2001, 2004). But reducing the length of either car increases the total risk to both drivers (Van Auken and Zellner 2005). Kebschull et al (2004) reported results based on computer crash simulations of three SUV designs (a baseline SUV, reduced-weight SUV, and increased-length SUV) in a nationally representative sample of real-world accidents. The computer simulation results indicated that the reducedweight SUV and the increased-length SUV both had improved overall safety compared to the baseline vehicle.

There are excellent reasons to believe that the relationship between safety and fuel economy in any give vehicle model can be positive and mutually enforcing. Here are recent research findings: Increasing vehicle weight is not inherent to safety. Vehicle size, specifically crush space, does provide safety in cer- tain types of crashes. The benefits of size have been confused with vehicle weight, because these two attributes are correlated across the vehicle fleet in any given year. And certain measures of size, such as bumper height and center of gravity, are detrimental to safety: high bumpers contribute to the aggressivity of trucks in crashes with cars, and a high center of gravity increases the propensity of SUVs and pickups to roll over. However, breakthroughs in materials and other technologies mean that historical correlations between weight and size, and thus safety, will not necessarily continue in the future.

These findings are supported by evidence that we now have in hand on vehicle fuel economy and safety.

\section{Reality \#1: Fuel economy standards bave not} stopped Americans from buying large autos.

Data reveal what a glimpse down any street in America shows-the size of the auto fleet has not uniformly shifted downward under CAFE standards. Instead, the upsizing of the vehicle fleet occurred at the same time that vehicle fuel economy increased significantly across the board.

Comparing model year 2005 with 1975 (prior to implementation of CAFE standards), it is clear overall that new vehicles got larger, not smaller (see figure; Heavenrich 2006). Today four of five new autos sold are midsize and large vehicles.

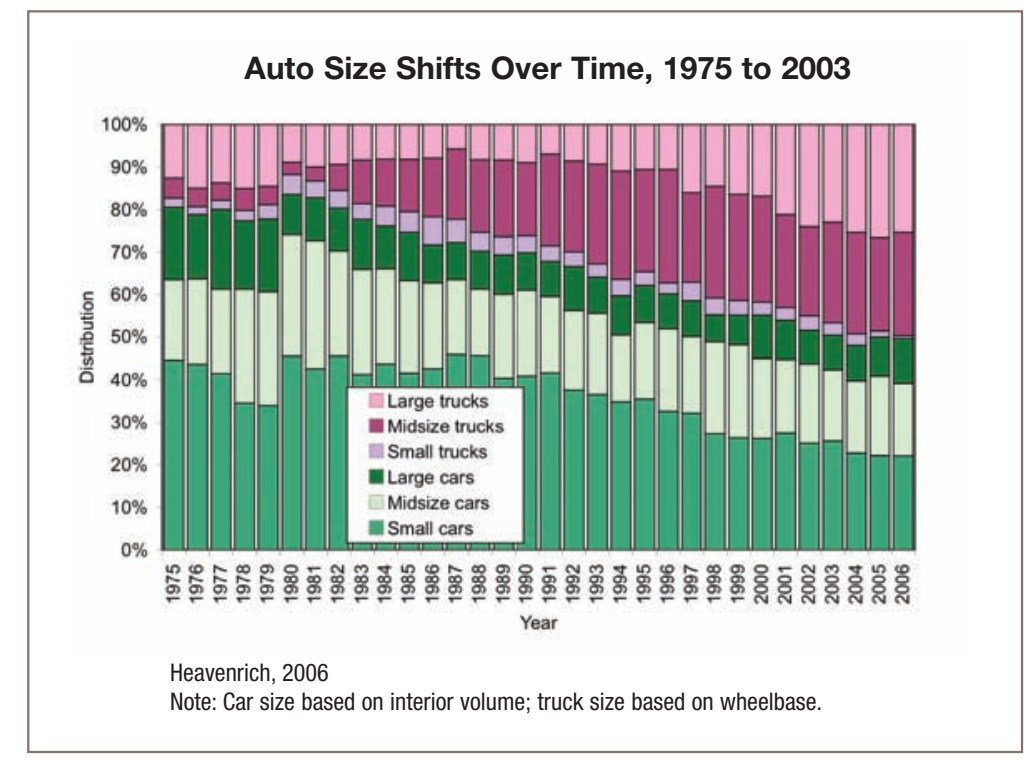


Reality \#2: Lightweight, fuel-efficient vebicles can be built for safety.

Poor vehicle design decisions cause unsafe autos to be built. A variety of technological options for increasing the energy efficiency of engines, transmissions, and accessories and reducing aerodynamic drag and rolling resistance are available that are unrelated to vehicle size or weight (NRC 2002). Technology rather than size or weight has been the predominant factor in past fuel economy improvements (Greene 2006).

Looking to the future, vehicle weight reduction in all vehicles offers opportunities for significant fleet-wide fuel economy improvements. But this will not cause unsafe autos to be built. The simple laws of collisions imply that velocity changes in a crash are dependent on relative, not absolute, mass, and they provide no $a$ priori reason to think that making all vehicles lighter would have either a good or bad effect. Thus, if all vehicles' weights were reduced by an equal percentage, there would be no effect on safety. The key intuitive argument linking fuel economy to vehicle weight to

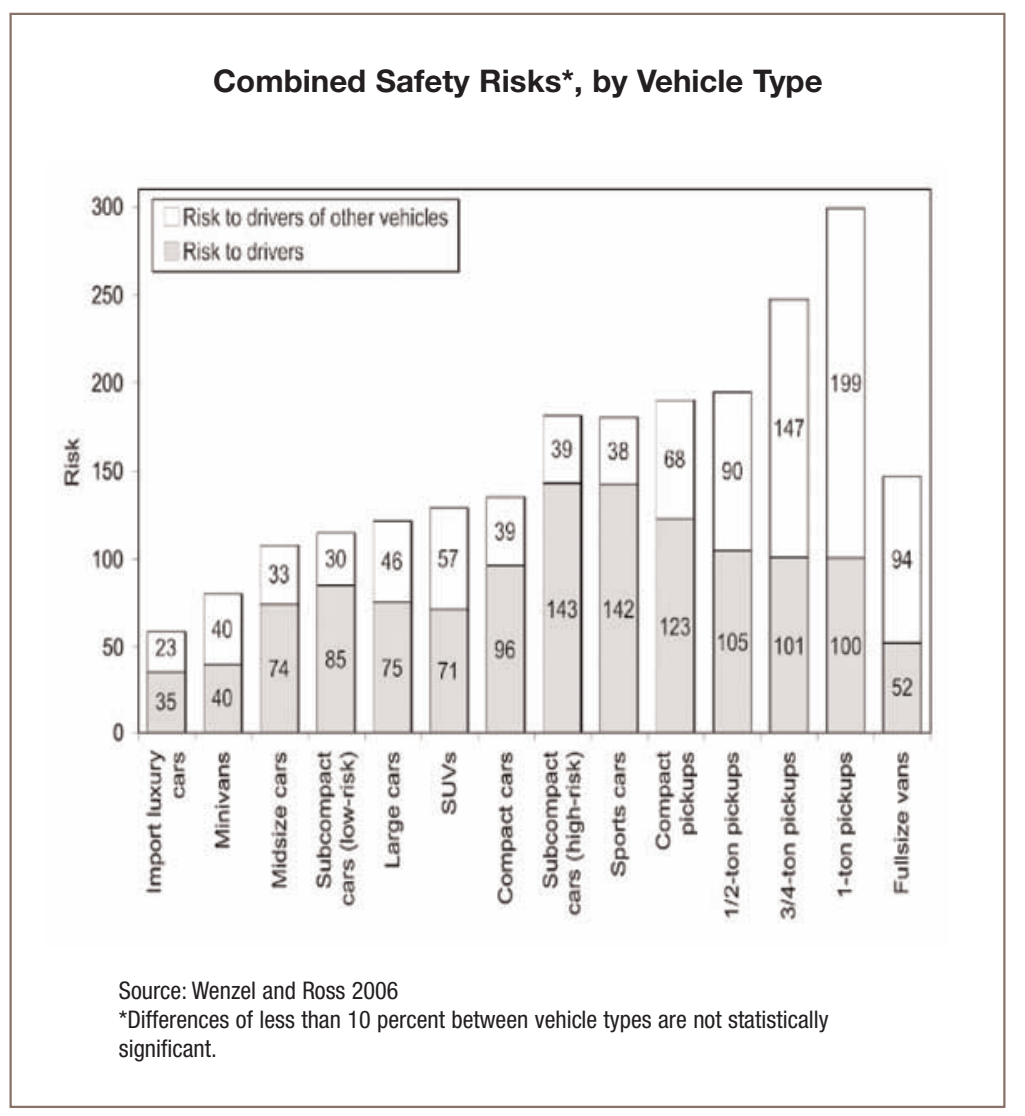

safety is actually not applicable to a fleet-wide reduction in weight (Greene 2006).

The greater the differences in vehicle masses, the worse the overall safety impacts. Not only are the heaviest, largest SUVs and pickups more aggressive toward other vehicles, they also have their own safety problems regarding rolling over and compromised crash avoidance capabilities. Wenzel and Ross (2006) suggest that it is useful to consider combined risks that include both the risk-to-driver and the risk-to-others (who share the road) when assessing overall vehicle safety.

The safest subcompact car models have a similar combined risk as larger and heavier midsize and large cars (see figure). The average SUV has a similar combined risk as the average compact car. Combined risk increases as pickup truck size increases. This counters the assertions that the largest, heaviest vehicles are inherently safer than smaller, lighter models, and that higher fuel economy translates into lower safety.

Today most of the vehicles with lower safety risks are Asian and German models, and those with higher safety risks are U.S. models. For example, the safest subcompact car models with the lowest risk to their own drivers are the VW Jetta (54), VW Beetle (67), Hyundai Elantra (86), and Honda Civic (88), while those with the highest risk are the Dodge Neon (179), Chevy Cavalier (168), Pontiac Sunfire (154), and Ford Escort (152) (Wenzel and Ross 2006).

Similarly, the safest SUV models with the lowest risks to their own drivers are Asian models_Lexus RX300/330 (24) and Honda CR-V (40), while those with the highest risk are U.S. models, including the Chevy Blazer (125), GM Jimmy/Envoy (110), Ford Explorer (96), and Chevy Tahoe (93) (Wenzel and Ross 2006). The safety differences between manufacturers are due, in part, to manufacturing decisions on their individual designs and the safety technologies incorporated into specific models. 


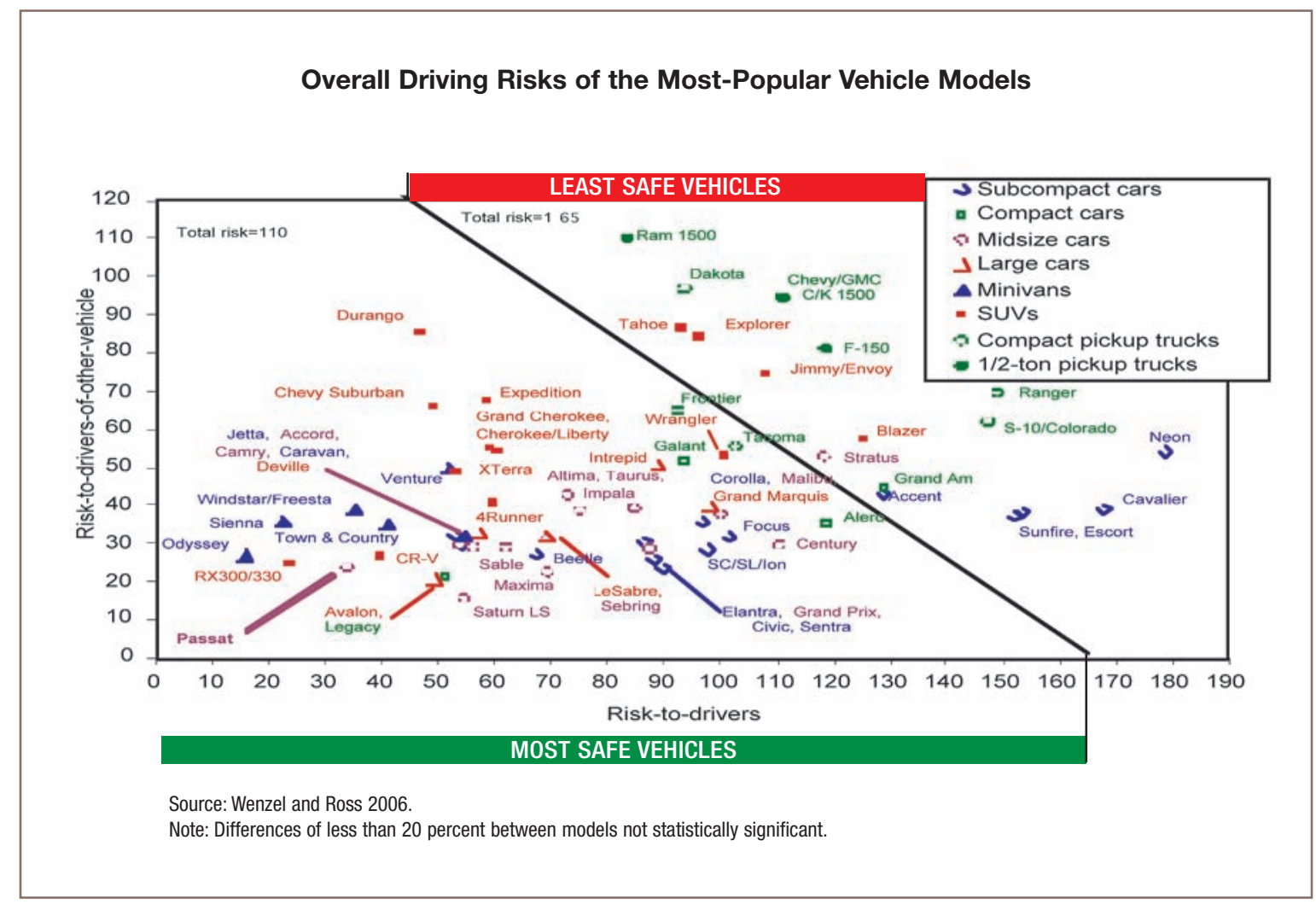

Reality \#3: Some SUVs and pickups pose safety risks for their drivers and others on the road.

Most Americans-55 percent of those surveyed in a recent TIME/CNN poll-believe SUVs are safer than cars because of their sheer size (Cloud 2003). But the perception of safety is not, in reality, safety. The truth is that the correlation between specific vehicle models and their fuel economy and safety is influenced greatly by design and driver behavior. Heavier SUVs and light trucks do not guarantee passenger safety. Witness SUVs' propensity to roll over and heavy pickup trucks' long stopping distance and inability to maneuver to avoid a crash. NHTSA's previous administrator, Jeffrey W. Runge, M.D., a former emergency-room doctor, stated that he wouldn't let his children drive any SUV with a high propensity to roll over, even "if it was the last one on Earth." Runge (2003) continued that consumers may sit in a vehicle and feel safe, "but gut instinct...isn't very good for buying a safe automobile." Moreover, SUV and light-truck aggressivity toward other vehicles makes them a risk to other drivers due to their incompatible design with other autos.
Some of the least safe vehicles on the road today- in terms of both safety to their own occupants and to other vehicles on the road—are the largest SUVs and trucks (see graph).

\section{Reality \#4: Fuel economy improvements bave} not occurred through market forces.

In the three decades since the first U.S. oil crisis in 1973, consumers have rarely signaled their desire for higher fuel economy. The reality is that it takes upwards of a 15 -year cycle for automakers to make and consumers to purchase an entirely new auto fleet (Greene 2006). Moreover, consumers have been found to value only the first three years of fuel savings, not the 14-year paybacks assumed in models (Greene 2004). These conditions have made it difficult for the market, unaided by public policies, to deliver an optimal level of fuel economy over time.

For the 2006 model year, less than 1 percent of all vehicles available for purchase achieved over $40 \mathrm{mpg} ; 3$ percent were above average in mileage $(30-39 \mathrm{mpg})$; 57 percent of the vehicles available scored an average 


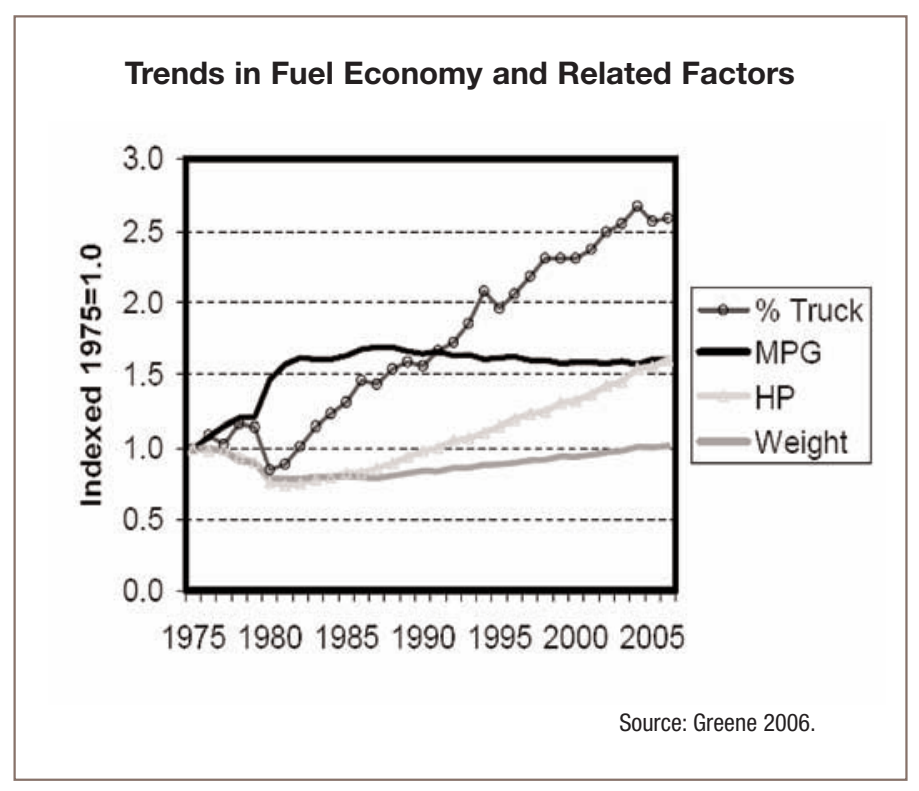

fuel economy (20-29 mpg); and 40 percent were under $20 \mathrm{mpg}$ (US EPA and US DOE 2007; CAS 2006). When record-high gasoline prices appeared at U.S. pumps in summer 2006, market forces could not instantaneously deliver a fuel-efficient product line-up.

Automakers at times have considered voluntary action to increase fuel economy. But market-driven improvements are slow. Enhanced power and performance have typically taken precedence over gasoline savings (see figure; Greene 2006).

\section{Concepts and Technologies Underpinning Safety and Fuel Economy}

The principal factors influencing vehicle fuel economy are relatively straightforward-the energy efficiency of the overall vehicle balanced against its demand for power. Driver behavior and the driving environment also influence fuel economy, but to a lesser degree.

The elements underpinning vehicle safety are more complex. The most important factors ${ }^{3}$ that influence safety are: drivers, the driving environment, and vehicle design, including crash avoidance, crashworthiness, and specific safety features. Drowsiness, inexperience, aggressiveness, alcohol, and distractions are some of the underlying factors that account for driving errors causing accidents. Poor weather, poorly designed roads, high speed limits, and stop-and-go traffic are examples of driving conditions that can lead to accidents.

Crash avoidance is the ability of a vehicle, through driver-controlled and automated handling and braking, to avoid a serious crash altogether. New electronic stability control (ESC) systems, which selectively apply the brakes at individual wheels, keep the vehicle from understeering or oversteering. ESC systems also cut power from the engine to help slow the vehicle. These measures help the driver maintain control of the vehicle and keep it on the road. NHTSA has proposed requiring ESC on all new light motor vehicles, which shows great promise in reducing serious injuries and fatalities.

Crashworthiness refers to the ability of a vehicle to protect its occupants once a crash has occurred. Standardized laboratory crash tests are used to simulate prescribed frontal and side crashes and rollovers. Engineers strive to minimize occupant deceleration, through vehicle weight and size (to absorb energy), and to protect occupants by designing a strong and rigid compartment (to prevent intrusion) that nevertheless tends to cushion those in other vehicles.

Crash compatibility is determined by the effect one vehicle's design and engineering has on others it comes into contact with in a crash. Crash compatibility is affected by the geometry of protective structures, relative vehicle and occupant compartment stiffness (stiffer vehicles and compartments provide greater protection, but can intrude more if the crashing vehicles' geometries do not match), and relative vehicle weights (heavier vehicles have lower crash energy absorption than lighter vehicles). Aggressivity is determined by designs that make a vehicle incompatible with and more dangerous to others it comes into contact with.

Vehicle designs can be optimized to improve safety and fuel economy performance. Many options are

\footnotetext{
${ }^{3}$ Researchers do not know the rank of the factors affecting vehicle safety; these are not listed in any particular order.
} 
available to increase fuel economy without compromising vehicle safety. Likewise, there are many avenues available to increase vehicle crashworthiness, crash avoidance, crash compatibility, and driver safety that have no bearing on fuel economy. It is entirely possible to build a safe motor vehicle that sips fuel-here's how.

\section{Fuel Economy Technologies}

Several technologies are readily available to increase fuel economy with no effect on safety: lower rolling resistance tires; smoother, lower body with redesigned mirrors for better aerodynamics; more efficient accessories such as electric power steering; integrated starter-generator; 7+ speed automatic-manual transmission; camless valve actuation, low-friction lubricants; variable valve timing and lift control; and gasoline direct-injection engines with lean burn and turbocharging, and other options (NRC 2002; UCS 2003).

Switching to diesel fuel may be another future option for improving fuel economy without impacting safety. Efficient diesel engines can boost fuel economy by about 20 percent or potentially much more. Clean diesel fuel and advanced diesel engines equipped with effective after-treatment devices could deliver additional fuel economy benefits without exacerbating public health risks through increased air toxic emissions.

Hybrid-electric drive vehicles (HEVs) run on electricity and gasoline and have the potential to deliver 30 to 60 percent higher fuel economy, without impacting vehicle safety (German 2007). Hybrid-electric vehicles (HEVs) can be configured to obtain different objectives, such as fuel savings, increased power, or additional auxiliary power for electronic devices and power tools. Some current hybrid vehicles deliver greater fuel savings than others, while some perform better in highway driving and others in city driving, depending on the type of hybrid system employed. Toyota's hybrid, Prius, gets an estimated 48/45 (city/highway) mpg, Honda's Civic hybrid drives $40 / 45$ miles on a gallon of gasoline, Ford's hybrid Escape 4WD reports 28/27 mpg, and the Saturn Vue gets 27/32 mpg (US EPA and US DOE 2007).

\section{Safety Technologies}

Similarly, there are many safety technologies that will not affect fuel economy such as side curtain air bags; front and rear crumple zones; electronic stability control; lower bumpers; rollover-activated belt pretensioners on all seats; stronger roof; and electronic seat-belt reminders on all seats (UCS 2006).

The fatality rate in rollovers in new SUVs has been cut in half over the past six years (see figure below). This decline can be attributed to manufacturers reducing the center of gravity and increasing the track width in newer SUV models, particularly the car-based "crossover" SUVs, making them more stable. This illustrates quite dramatically how vehicle design affects fatality rates in new vehicles over time.

When it comes to multi-vehicle crashes, vehicle safety does not only entail how well designed your vehicle is; it also depends on the compatibility between vehicles in the event of an accident. Differences in vehicle structural geometry may translate into one vehicle intruding into the compartment of another. Likewise, stiffer vehicles will crush less-than-softer vehicles,

\section{Driver Fatality Rates in Rollover Crashes in One- to Three-Year-Old Vehicles, By Year and Vehicle Type}

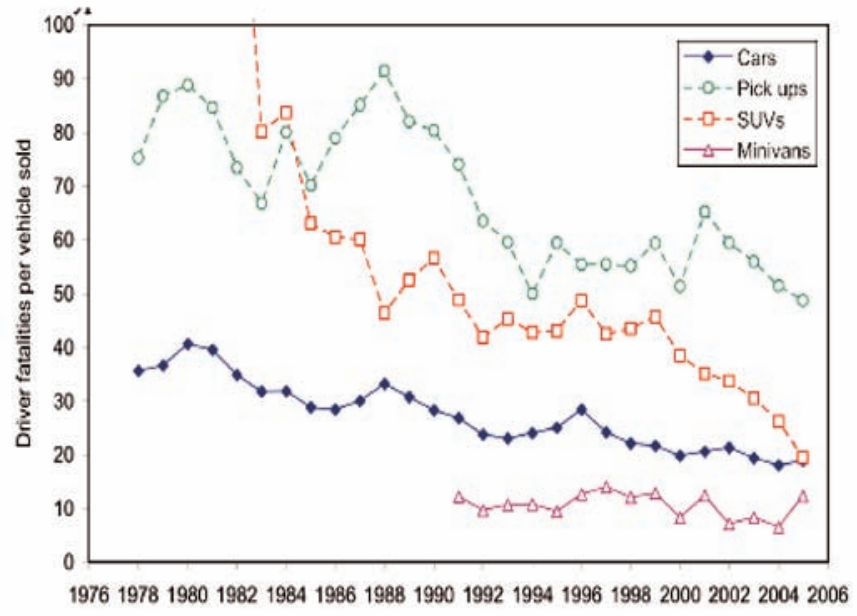

Source: Wenzel and Ross 2006 
which can increase intrusion into the occupant compartment of the softer vehicle. And relative vehicle weights can mean that the lighter vehicle has higher crash energy absorption. This makes design configuration and geometry of vital importance in building a safer vehicle.

Crashworthiness is enhanced when occupant deceleration is minimized and occupants are adequately protected in the vehicle itself. Achieving this translates into ample space for the vehicle to crush and absorb the energy transferred in a crash, as well as the strength and rigidity to prevent intrusion into the vehicle in an accident. The more cushioned and protected the occupants are, the better safeguarded they are. Research has shown that reductions in curb weight would decrease fatalities, while reductions in wheelbase would increase fatalities, in both one-and two-vehicle crashes (Van Auken and Zellner 2005b).

The passive safety of smaller vehicles depends largely on the vehicle's structural design and the specific materials used. And while smaller (and lighter) vehicles have less "crush" space to absorb deceleration energy in a crash, they typically have a shorter braking distance and may have better pre-crash dynamics to avoid collisions altogether ${ }^{4}$ (German 2006).

To further improve the safety of vehicles without compromising fuel economy, manufacturers can develop stronger vehicle compartments. The proportion of high-strength materials can be increased for greater overall integrity in crashes without increasing overall weight. In order to reduce any given vehicle's aggressivity to other vehicles, stronger structure should be compensated for by greater vehicle crush outside the passenger compartment. Optimized designs (with simulation) and material innovations make it possible to balance the need for improved performance with the need for weight control (German 2006).

Auto manufacturers have been improving vehicle safety on the margin for decades. Some have been more innovative than others. For example, Ford first introduced seat belt reminders and developed roll-stablity control (Prasad 2007). And as of 2005, Honda's vehicles had vehicle stability assist on light-duty trucks (82 percent), side curtain air bags (60 percent), side-supplemental restraint system air bags (78 percent), and automated braking systems (85 percent) (German 2006). In 2006, the Honda Civic added telescoping steering wheels (to prevent driver impact injury), highstrength steel in about 50 percent of its body, ACE (Advanced Compatibility Engineering) body structure, and greater rigidity for improved handling. Manufacturers are now installing electronic stability control; in the 2004 model year, 11 percent of cars and 13 percent of SUVs had ESC as standard equipment, while another 3 percent of cars and 13 percent of SUVs had it as an option (IIHS 2007). In 2007, NHTSA passed a rule requiring ESC be installed on all passenger vehicles (up to 10,000 pounds) which will be phased in between 2008 and 2011 (CFR 2007).

\section{Vebicle Weight}

In addition to these technologies to independently increase fuel economy and safety, reductions in vehicle weight, coupled with improved design, could simultaneously increase both fuel economy and safety. For example, the softer and lighter uni-body design in passenger cars has distinct safety advantages over the stiffer and heavier body-on-frame designs typically used in light-duty trucks. Early "crossover" SUV models, using uni-body design, have lower risks, both to their own drivers and to drivers of other vehicles, than conventional truck-based SUV models (Wenzel and Ross, 2005).

In the 2005 model year, half of SUVs were crossovers (car-based SUV models) with uni-body design. And Honda's Ridgeline pickup truck also utilizes uni-body design. Strong, lightweight materials, such as aluminum, magnesium, light steels, and carbon composites, offer options to better optimize energy management and mass for all vehicles. Using a systems approach, where vehicles are designed to take full

\footnotetext{
${ }^{4}$ The Insurance Institute for Highway Safety (IIHS) finds that smaller, lighter vehicles are involved in more crashes. This is based on insurance claim data that indicate that smaller cars incur higher collision insurance losses per vehicle than larger cars. It is not clear, however, that the higher losses are because smaller cars are involved in more crashes, or because the damage to smaller cars is greater, and therefore more costly. (Nevertheless, IIHS believes that there is ample opportunity to improve fuel economy without harming the occupant protection characteristics of vehicles.)
} 
advantage of these new materials, can revolutionize vehicle safety and fuel economy simultaneously.

Vehicle mass (or weight) is an undisputed factor in vehicle fuel economy. To illustrate the dependence, consider that a mass reduction of 10 percent, coupled with a reduction in engine size, can increase fuel economy by 8 percent (An, Friedman, and Ross 2002). It's the quick and easy fix that automakers hastily turned to following the 1970s' oil crises to readily transform their bulky gas-guzzlers into "overnight" gas-sippers. The major problem was that these vehicles were poorly designed. While a reduction in vehicle mass is one important technique for improving fuel economy, it is certainly not the only, or even the most effective, one. Many experts believe that weight reduction is not the priority issue for increasing fuel economy as we move forward, at least in the short term (Greene 2006).

In another illustrative exercise, researchers concluded that the safety effect of a 100-pound weight reduction would vary widely with crash type, increasing fatalities in some types of crashes and reducing them in others. For example, reducing the weight of the heaviest light trucks was predicted to reduce fatalities in certain types of crashes (between heavy trucks and other cars and light trucks) (Kahane 2003).

Additional opportunities remain to safely achieve reduction in vehicle mass. Automakers can:

- Design optimal components and local structures to reduce mass.

- Change the basic vehicle structure of conventional body-on-frame SUVs and pickups by using car-based uni-body design (as in the "crossover SUVs" and in the Honda Ridgeline pickup truck).

- Adopt lighter propulsion components, especially small engines capable of switching to high power by operating at high speed or with turbocharging, to maintain drivability and maximum consumer appeal (Shahed 2006).

- Use simpler and lighter transmissions, such as automatic "manual" or double-clutch technologies or continuously variable transmissions.

- Continue to increase the content of light- weight materials, such as high-strength steels supported by advanced steel forming, light metals (aluminum and magnesium), and fiberreinforced plastics (DeCicco 2005; Lovins et al. 2005).

If automakers pursue this strategy, vehicle weight reduction should be accompanied by compatible design elements to overcome the intrinsic property whereby in a collision with another vehicle or roadside object, the lighter of the pair is more strongly decelerated. Depending on the details of the crash, the stronger deceleration may create a greater risk to the occupants in a lighter vehicle. But this additional risk is relatively small compared to what frequently happens in a serious crash-intrusion into the passenger compartment; vehicle rollover; or failure of the restraints to keep occupants away from contact with hard interior surfaces (Ross, Patel, and Wenzel 2006).

\section{Technology Costs}

The National Academy of Sciences' report on CAFE standards indicated that for passenger cars, weightneutral fuel economy increases of from 12 percent for subcompacts to 27 percent for large cars would be cost effective, while for light trucks, greater improvements were achievable at marginal costs equal to the marginal value of fuel saved (from 25 percent for small SUVs to 42 percent for large SUVs) (NRC 2002).

The NAS study was completed before the increase in gasoline prices in the past few years. David Greene updated the NAS results using more current gasoline prices. In June 2006, Greene found that, assuming a gas price of $\$ 2.50$ per gallon, fuel economy could be increased 41 percent, with net consumer savings of $\$ 2,338$. Assuming a gas price of $\$ 3.55$ per gallon, fuel economy could be increased 57 percent, with a net consumer saving of $\$ 3,190$.

In their report, Building a Better SUV, the Union of Concerned Scientists estimates that a boost in SUV fuel economy to 36.3 miles per gallon, coupled with new safety features and weight reduction, could save 2,900 lives annually at a total cost of under $\$ 3,000$ per vehicle. The lifetime fuel cost savings is about $\$ 4,400$, with a projected payback of about three years. However, if the price of gasoline increases over $\$ 2.50$ a 
gallon, the payback from gasoline savings becomes even more favorable (UCS 2006).

Select vehicles with short payback times are already available on showroom floors today. Consumer Reports (2006) found that at least two current hybrid vehicle models recovered their price premium in the first five years and 75,000 miles of ownership. Hybrid Toyota Prius owners save \$406, and Honda Civic Hybrid owners save $\$ 317$, compared to the Toyota Corolla LE sedan and the Honda Civic EX sedan, respectively. The economic savings of these models are even greater if one factors in federal (and state, if available) tax credits. (It is rumored, however, that Toyota and Honda are subsidizing the added up-front cost of these hybrid models.) Future hybrid models could have even faster payback times if they do not trade off fuel economy for greater power.

In terms of the costs of safety improvements, NHTSA estimated that over 300,000 lives had been saved by vehicle safety technologies since 1960 , and government-mandated safety standards had added about $\$ 840$ in vehicle costs. NHTSA's cost-effectiveness calculations examined past braking improvements, safety belts, air bags, energy-absorbing steering columns, child safety seats, improved roof strength and side impact protection, shatter-resistant windshields, and instrument panel upgrades. As of 2005, the agency had not evaluated newer technologies such as side air bags, electronic stability control systems, lightweight materials, or a host of other promising vehicle safety technologies (TRB 2005). NHTSA is currently evaluating newer safety technologies; this should include the many safety technology and policy advances that result in lower fatality rates in other nations.

Researchers abroad have concluded that several other vehicle safety technologies (some of which were developed by U.S. automakers) are cost effective, including seatbelt reminders, accident data recorders, electronic stability control, improved blind spot mirrors, intelligent speed adaptation, alcohol ignition interlocks, conspicuous vehicle marking, under-run protection, daytime running lights, and lane departure warnings (Odgaard and Bogelund 2007).

\section{Research Findings on Vehicle Fuel Economy and Safety}

The workshop that informed this report considered the most recent evidence on fuel economy and safety, including important peer reviewed studies published since the National Research Council (NAS) 2002 report on fuel economy standards. A wide array of automotive analysts have concluded that there are many ways to sip fuel while saving lives. (see Appendix A for list of participants). The key technical findings that should guide future policy design are:

1. Most technologies to increase fuel economy do not affect safety; most technologies to increase safety do not affect fuel economy.

2. There are many technological options for increasing vehicle fuel economy; reducing weight via material substitution is but one of many available strategies.

3. Strategically reducing car weight while improving vehicle structure, using advanced materials and designs, can simultaneously increase fuel economy and safety.

4. Reducing the weight of heavier SUVs and pickup trucks increases fuel economy and improves the safety of all vehicles on the road.

Different researchers who participated in the workshop have their own specific findings that relate to vehicle safety and fuel economy. Each draws important conclusions that can be used to enlighten future policymaking efforts (see Appendix B).

\section{Challenges and Barriers}

Experts remind us that vehicle design is crucial, but there are other confounding factors in the safety/fuel economy equation; road hazards, driving errors, and the driving environment present distinct challenges. Examples abound: Aggressive driving reduces safety and fuel economy. Poorly maintained vehicles reduce fuel economy and safety. Poorly designed rural roads reduce safety and can affect fuel economy under lessthan-ideal driving conditions. Poor driving skills reduce safety and fuel economy. And speeding (along 
with higher speed limits) reduces safety and fuel economy. Moreover, safety testing and models developed have limitations. Consumer information programs are limited by funding and other factors. Long lead times can delay goals. And consumers face trade-offs between vehicle performance and broader social goals when making purchase decisions. While these factors raise certain challenges, they should not be an excuse for inaction. Policy designs should reduce barriers and compensate for trade-offs, whenever possible.

\section{Safety Testing Limitations}

Crash tests cannot replicate real-world crashes-especially in side impacts. The inexact science and imperfect regime of testing vehicles may not always yield the best solutions. This can result in unintended consequences. For example, left side crashes are worse than frontal crashes possibly due to a testing regime that has historically focused on front-end collision testing. Manufacturers' design changes made to improve frontal crash-test scores resulted in producing vehicles (especially pickups and SUVs) that are more aggressively designed than they need to be (especially in side impacts with other vehicles).

Crash tests do not reflect real-world vehicle compatibility. Analysts have historically considered only the risk to occupants of the vehicle in question. In a larger social context, all those on the road, including the occupants in other vehicles, deserve to be protected. A carefully designed program of two-vehicle crash tests (that measure the aggressivity of car vs. SUV or pickup collisions) merits introduction.

Crash tests focus on crashworthiness, not crash avoidance. Heavier vehicles tend to have longer stopping distances and reduced maneuverability compared to lighter vehicles. As an important element in vehicle safety, crash avoidance merits greater consideration in new testing regimes.

\section{Model Limitations}

The limits of models used to determine the feasibility and cost effectiveness of fuel economy and safety improvements can create unnecessary barriers for future regulations. New technologies can introduce uncertainties in models. Accurate estimates of the costs of material substitution and weight reduction, for example, could make current models more useful in terms of policy design and assessment. Continuously updating models with up-to-date technology information requires resources allocated to these purposes.

\section{Consumer Information Limitations}

Limits to the vehicle safety testing regime can further confuse consumers. As vehicle manufacturers strive to improve the designs of their new vehicles to ensure that they do not receive low safety scores, they can steer away from better designs. But the injury risks in actual driving only weakly correlate with crash test results (Newstead, Farmer, Narayan, and Cameron 2003). Yet to a growing number of consumers, safety ratings form the basis for purchase decision. Vehicles are designed to be crashworthy based on tests, not real-world conditions. This information can confuse consumers.

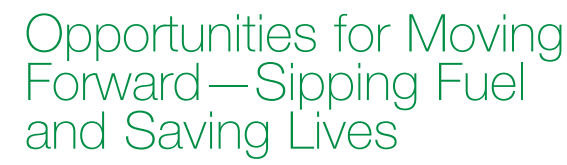

In 2004, the fuel economy of the average new passenger vehicle dropped to its lowest point since 1980, and in 2005, highway fatalities reached their highest level since 1990. The question remains whether the next decade and beyond will continue these troublesome trends. The future designs of U.S. cars, SUVs, and light trucks will be influenced by public policies, or the lack thereof. Thousands of lives, millions of injuries, billions of gallons of gasoline, millions of tons of carbon, and billions of U.S. consumer dollars each year hang in the balance. Congress is now considering new policies to increase the fuel economy of new automobiles in order to address many national concerns.

If the overarching goal is to pursue both safety and fuel economy, then vehicle design is the key. Manufacturers can make tremendous strides with technologies, and consumers can make better purchase decisions if they have complete information on a large selection of safe, high fuel economy vehicle models. There are numerous opportunities available to improve vehicle safety, including electronic stability control to reduce vehicle rollovers; stronger roofs and pillars to improve crashworthiness in rollovers; compatible frontal heights to reduce truck-car fatalities and injuries; side curtain air 
bags to protect occupants in side crashes; improved seatbelt technology to protect occupants in all crashes; and many other designs and technologies.

Technologies also exist to improve fuel economy: 7 speed automatic-manual transmissions; integrated starter-generators; low-friction lubricants; electronic variable valve and lift control; lean burn gasoline direct-injection engines with turbocharging; low rolling resistance tires; bodies with better aerodynamics; and more efficient accessories. In addition, use of new lightweight materials to reduce weight while maintaining size will increase fuel economy without affecting safety.

In addition to these technologies, there are several policy strategies to further improve fuel economy and safety:

- Set fuel economy and safety performance goals at cost-effective levels, and allow adequate time for phase-in of vehicle redesigns.

- Develop near-term goals that use existing technological potential and long-term goals to spur continued innovation.

- Apply the same fuel economy and safety standards consistently to all vehicle types (cars, SUVs, and pickup trucks).
- Encourage modification in driver behavior (speed limits, seatbelt use, drunk driving laws, etc.) to improve fuel economy or safety.

\section{These strategies would usher in a new fleet of higher fuel economy, safer passenger vehicles.}

\section{Well-designed targets mean that industry can put its genius to work to meet these goals.}

The overarching question is: what are our national priorities? The compounded costs of vehicles that sip fuel and save lives are high—lost lives, unnecessary injuries, incurred medical expenses, reduced productivity, compromised national security, increased funding for national defense, resource skirmishes and wars, trade deficits, air pollution, and a host of dire impacts from climate change. Vehicles have long lifetimes. The autos produced today will eventually be driven by our children. Fuel economy can be dramatically improved without compromising safety. Safety can be bolstered without sacrificing fuel economy. Now is the time to deliver a new generation of safer, higher-fuel-economy vehicles for the next generation of Americans. 
Appendix A

List of Expert Attendees and Affiliation

Participants at the October 4, 2006 Hewlett Foundation Vehicle Safety and Fuel Economy Meeting

\begin{tabular}{|c|c|c|c|}
\hline First Name & Last Name & $\underline{\text { Title }}$ & Organization \\
\hline Mike & Brylawski & Senior Consultant & Rocky Mountain Institute \\
\hline Joan & Claybrook & President & Public Citizen \\
\hline Dainius & Dalmotas & Consultant & D.J. Dalmotas Consulting \\
\hline Danielle & Deane & $\begin{array}{l}\text { Program Officer, } \\
\text { Environment }\end{array}$ & The William and Flora Hewlett Foundation \\
\hline John & DeCicco & $\begin{array}{l}\text { Senior Fellow, } \\
\text { Automotive Strategies }\end{array}$ & Environmental Defense \\
\hline Ken & Digges & $\begin{array}{l}\text { Director of Biomechanics } \\
\text { and Automotive } \\
\text { Safety Research }\end{array}$ & $\begin{array}{l}\text { National Crash Analysis Center } \\
\text { The George Washington University }\end{array}$ \\
\hline Clarence & Ditlow & Executive Director & Center for Auto Safety \\
\hline Michael & Freedhoff & Senior Policy Associate & $\begin{array}{l}\text { Office of Representative } \\
\text { Edward J. Markey (D-MA) }\end{array}$ \\
\hline David & Friedman & $\begin{array}{l}\text { Research Director, } \\
\text { Clean Vehicles Program }\end{array}$ & Union of Concerned Scientists \\
\hline John & German & $\begin{array}{l}\text { Manager, Environmental } \\
\text { and Energy Analysis }\end{array}$ & American Honda Motor Co. \\
\hline David & Greene & $\begin{array}{l}\text { Senior Research Staff } \\
\text { Member, Center for } \\
\text { Transportation Analysis }\end{array}$ & Oak Ridge National Laboratory \\
\hline Hal & Harvey & $\begin{array}{l}\text { Program Director, } \\
\text { Environment }\end{array}$ & The William and Flora Hewlett Foundation \\
\hline Eric & Haxthausen & Economist & Environmental Defense \\
\hline Ralph & Hitchcock & Consultant & American Honda Motor Co. \\
\hline Yoshiji & Kadotani & Chief Engineer & American Honda Motor Co. \\
\hline Robert & Kaeser & $\begin{array}{l}\text { Professor, Department of } \\
\text { Technology, Computer } \\
\text { Science, and Natural Scie }\end{array}$ & Zürich University of Applied Sciences \\
\hline
\end{tabular}

Science, and Natural Sciences 


\begin{tabular}{|c|c|c|c|}
\hline First Name & Last Name & $\underline{\text { Title }}$ & Organization \\
\hline Deron & Lovaas & $\begin{array}{l}\text { Vehicles Campaign Director } \\
\text { and Deputy Director of the } \\
\text { Smart Growth and } \\
\text { TransportationProgram }\end{array}$ & Natural Resources Defense Council \\
\hline Amory & Lovins & Chief Executive Officer & Rocky Mountain Institute \\
\hline Adrian & Lund & President & Insurance Institute for Highway Safety \\
\hline Laura & MacCleery & Congress Watch Director & Public Citizen \\
\hline Carl & Nash & $\begin{array}{l}\text { Adjunct Professor of } \\
\text { Engineering }\end{array}$ & $\begin{array}{l}\text { National Crash Analysis Center } \\
\text { The George Washington University }\end{array}$ \\
\hline Bob & Noland & $\begin{array}{l}\text { Reader (Associate Professor) } \\
\text { in Transport and } \\
\text { Environmental Policy }\end{array}$ & Imperial College London \\
\hline Franklin & Nutter & President & Reinsurance Association of America \\
\hline Deena & Patel & Postdoctoral Fellow & $\begin{array}{l}\text { Physics Department, } \\
\text { University of Michigan }\end{array}$ \\
\hline Jason & Patlis & $\begin{array}{l}\text { Deputy Chief of Staff, } \\
\text { Majority Staff }\end{array}$ & House Committee On Science \\
\hline David & Pittle & Consultant & \\
\hline Priya & Prasad & $\begin{array}{l}\text { Ford Technical Fellow, } \\
\text { Safety Research and } \\
\text { Development }\end{array}$ & Ford Research and Innovation Center \\
\hline Marc & Ross & $\begin{array}{l}\text { Professor Emeritus } \\
\text { Physics Department }\end{array}$ & University of Michigan \\
\hline Joe & Ryan & $\begin{array}{l}\text { Managing Director for } \\
\text { Latin America and Program } \\
\text { Officer, Environment }\end{array}$ & The William and Flora Hewlett Foundation \\
\hline Steven & Schmidt & $\begin{array}{l}\text { Research Administrator, } \\
\text { Automotive Technical } \\
\text { Research Unit }\end{array}$ & State Farm Insurance Co. \\
\hline Robert & Shull & $\begin{array}{l}\text { Deputy Director for } \\
\text { Auto Safety \& Regulatory } \\
\text { Policy }\end{array}$ & Public Citizen \\
\hline David & Snyder & $\begin{array}{l}\text { Vice President and } \\
\text { Assistant General Counsel }\end{array}$ & American Insurance Association \\
\hline
\end{tabular}




$\begin{array}{llll}\text { First Name } & \text { Last Name } & \text { Title } & \text { Organization } \\ \text { Todd } & \text { Summe } & \begin{array}{l}\text { Market Development } \\ \text { Manager }\end{array} & \text { Alcoa, Inc. } \\ \text { Stephen } & \text { Summers } & \text { Staff Engineer } & \text { National Highway Traffic } \\ \text { Mike } & \text { Van Auken } & \text { Principal Engineer } & \text { Safety Administration } \\ \text { William } & \text { Walsh } & \text { Consultant } & \text { Dynamic Research, Inc. } \\ \text { John } & \text { Waters } & \text { Team Leader, } & \text { Rocky Mountain Institute } \\ \text { Tom } & \text { Wenzel } & \text { Scientist } & \text { Lawrence Berkeley National Laboratory } \\ \text { Blake } & \text { Zuidema } & \text { Director, Product } & \text { Mittal Steel Company - USA R\&D Center }\end{array}$




\section{Appendix B \\ Summary of Workshop Papers and PowerPoint Presentations}

Tom Wenzel (Lawrence Berkeley National Laboratory) and Marc Ross (University of Michigan), in their briefing paper, "Increasing the Fuel Economy and Safety of New Light-Duty Vehicles," find that vehicle design is the key. New safety technologies and lightweight materials will decouple any historical relationship among weight, size, and safety. Vehicle weight and size provide only partial protection; they don't help in side crashes, and they have little effect on the propensity to roll over. Heavier and larger trucks and SUVs are very unsafe-they kill other drivers. These vehicles are much more aggressive toward other vehicles than are lighter and smaller vehicles. And their aggressivity increases as their size/weight increases. Therefore, reducing frontal height and stiffness is necessary to reduce larger truck/SUV aggressivity, and increasing frontal height, side stiffness and crush space in cars is necessary to improving their relative safety on the road with large trucks. Compact pickups are more aggressive than large cars of comparable mass, and compact truck-based SUVs are more aggressive than midsize cars of comparable mass. Finally, crossover SUVs are safer and more efficient than truck-based SUVs (17 percent higher fuel economy for same interior volume; lower overall safety risks with lower fronts and unibody design).

David Greene from Oak Ridge National Laboratory, in his policy briefing paper, "Fuel Economy Policies and Highway Safety," makes several important assertions. It is not fuel economy per se that affects vehicle safety-no one asserts that the amount of fuel a vehicle consumes has a direct effect on safety. The relationship between fuel economy and highway safety is complex, ambiguous, poorly understood, and not measurable by any known means at the present time (NRC 2002). In fact, there is evidence supporting the current view that there has been no relationship between fuel economy and traffic fatalities. Generally ignored is the fact that engine size and horsepower affect fuel economyreducing engine size and power are also options open to manufacturers to increase fuel economy. If all vehicles' weights are reduced by an equal percentage, there would be no effect on safety. Thus, the key intuitive argument for a link from fuel economy to vehicle weight to safety is actually not applicable to a fleetwide reduction in weight. Recently published statistical analysis of the correlation between fuel economy and traffic fatalities, covering the period from 1966 to 2002, have either produced inconclusive results using state-level data (Noland 2004) or have conclusively demonstrated that there was no such correlation at the national level (Ahmad and Greene 2005). The bottom line: significant technological options are available to manufacturers with which greenhouse gas emissions can be reduced and fuel economy improved without affecting vehicle size or weight.

Amory Lovins and his team from the Rocky Mountain Institute, in their book, Winning the Oil Endgame, believe that the key to the next vehicle efficiency breakthrough will be ultra-light materials now entering the market. Taking as much as another ton out of our vehicles was long assumed to be unsafe and unaffordable. Today, light-weighting needn't be either, thanks to advances in both metals and plastics. Extra-strong steel alloys and innovative structures could double automotive fuel economy and improve safety at no extra cost. BMW is currently developing carbon fiber for use in series production cars because it's 50 percent lighter than steel and performs extremely well in vehicle crash testing. And adding size without weight provides protection without hostility.

David Friedman with the Union of Concerned Scientists, in his presentation, "Optimizing Fuel Economy and Safety to Avoid Tradeoffs," posits that it is entirely possible to improve fuel economy without impacting safety because many fuel economy technologies are out there with no obvious safety drawbacks. Likewise, it is possible to improve safety without impacting fuel economy because there are many safety approaches with no major fuel economy drawbacks. Thus fuel economy and safety can move forward on parallel tracks. Vehicle weight increases required for safety improvements do not have significant impacts on fuel economy. Finding a comfortable fit between fuel economy and safety means choosing technologies 
wisely. Lower center of gravity both reduces rollovers and improves car/truck compatibility while reducing aerodynamic drag. Material substitution and system redesigns enhance safety while reducing weight. The key is to avoid unnecessary trade-offs between vehicle safety and fuel economy; both are worthy national priorities.

John German, the Manager of Environmental and Energy Analysis at American Honda Motor Company, in his presentation, "Improving Safety Without Impacting Fuel Economy," claims that today's advances in crash technology and materials require a more sophisticated analysis to analyze separately the effect of size and weight on safety.

But overall, a reduction in light-truck weights decreases fatalities, while light-truck wheelbase and/or track reduction increases fatalities. Not just Honda, but all manufacturers are working to improve the compatibility of their vehicles on the road to increase occupant safety. While advanced crash safety technology and crash avoidance technology will not change any underlying relationship between safety and size/weight nor fully account for driver behavior, these technologies will reduce the overall safety impact by reducing the magnitude of all injuries sustained. And, finally and most important, the technologies Honda is developing will improve the situation considerably_lightweight materials can both reduce overall fatalities and improve fuel economy.

Adrian Lund, with the Insurance Institute of Highway Safety (IIHS), in his PowerPoint presentation at the workshop, "Reflecting Vehicle Safety in Insurance Costs," identifies the insurance coverage variables that enable IIHS data collection of the costs associated with accidents. In IIHS's data set, which focuses on the private questions of loss rather than on larger social concerns of vehicle safety, IIHS finds that small cars incur greater insurance losses than larger cars, but the largest 4WD SUVs incur similar or even greater losses than smaller SUVs. Heavier pickup trucks, SUVs, sports cars, and luxury cars have greater relative bodily injury liability outlays overall than their lighter counterparts. The inverse is true of non-luxury, non-sport car models. IIHS acknowledges that vehicle fuel economy can be increased without affecting safety, and safety can be increased without affecting vehicle fuel economy. However, auto safety improvements can have different effects on different insurance coverage. The ability of IIHS to evaluate the effect of vehicle safety improvements, such as head restraints with better geometry, on injury claims is limited because IIHS can only evaluate injury insurance losses in no-fault states where a driver's own insurance covers his or her injury expenses. Injuries related to whiplash are the single largest source of injury claims-24 percent of all injury losses. Fatality insurance claims are less costly than serious injury claims, which can entail long-term hospitalization, expensive surgeries, loss of earning potential, etc. In sum, IIHS believes that there is ample opportunity to improve fuel economy without harming the occupant protection characteristics of vehicles.

Adrian Lund (IIHS), in his PowerPoint presentation at the workshop, "CAFE and Motor Vehicle Safety: Policy Makes a Difference," concludes that past improvements in fuel economy have cost lives, but that improvements in fuel economy in the future are possible without harming safety through the use of technology. IIHS analyzed occupant death rates by vehicle type and weight, and found that car and pickup occupant death rates decrease as weight increases, while other vehicle death rates increase as pickup and SUV weight increases. IIHS concludes that despite huge improvements in vehicle safety, the effects of car size and weight still exist. In its referenced report, "Faster Travel and the Price We Pay," IIHS states that improvements in fuel economy are possible without harming safety. The link is new fuel-efficiency technologies. Other opportunities beyond vehicle technologies also exist to reduce fuel use and improve safety, including lowering speed limits and replacing signal lights with roundabouts/traffic circles. For two decades automakers have been pumping up the performance capabilities of new cars. From 1980 to 2002, the average horsepower-to-weight ratio-a key measure of performance-increased by 50 percent. (IIHS 2003). Even the Toyota Camry is hyped for performance. In a commercial for the Camry, a driver goes backward, jumps hilltops, and swerves across four lanes. The tagline: "My car makes me feel like the road is my playground." Less safety and more gas guzzling are the prices we pay for today's "muscle" cars (IIHS 2003). 
Workshop Materials Available Online:

www.theicct.org

www.hewlett.org 


\section{References}

Ahmad, S., and Greene, D.L. 2005. Effect of fuel economy on automobile safety: A reexamination. Transportation Research Record 1941. Washington, DC: Transportation Research Board of the National Academies.

An, F., Friedman, D., and Ross, M. 2002. Near-term fuel economy potential for light-duty trucks. SAE Technical Paper Series 2002-01-1900. Warrendale, PA.

Arbelaez, R.A., Baker, B.C., and Nolan, J.M. 2005. Delta Vs for IIHS side impact crash tests and their relationship to real-world crash severity. Proceedings of the 19th International Technical Conference on the Enhanced Safety of Vehicles, paper number 05-0049. Available at www-nrd.nhtsa.dot.gov/departments/nrd-01/esv/19th/esv19.htm

Ball, Jeffrey. 2003. Ford delays plans to boost fuel economy of its SUVs. Wall St. Journal, April 18.

Center for Auto Safety (CAS). 2006. "Consumers can save money and oil without sacrificing choice." Washington, DC, February 27.

Cloud, John. 2003. Why the SUV is all the rage. Time, February 16.

Code of Federal Regulations (CFR). 2007. "Federal Motor Vehicle Safety Standards; Electronic Stability Control Systems; Controls and Displays.” 72 Fed. Reg. 17,236, April 6.

Consumer Reports. 2006. The dollars \& sense of hybrids. April.

Davis, Stacy. 2006. Transportation energy databook: Edition 24, Oak Ridge National Laboratory, Table 1.8.

DeCicco, J. 2005. Steel and iron technologies for automotive lightweighting." New York: Environmental Defense.

Edwards, M., Happian-Smith, J., Davies, H., Byard, N., and Hobbs, A. 2001. The essential requirements for compatible cars in frontal collisions. Proceedings of the 17th International Technical Conference on the Enhanced Safety of Vehicles, paper number 158. Available at http://www-nrd.nhtsa.dot.gov/pdf/nrd-01/Esv/esv17/Proceed/search.pdf

Energy Information Administration (EIA). 2006. International Energy Annual 2004.

EIA. 2007a. Basic Petroleum Statistics, March.

EIA. 2007b. Petroleum Navigator.

Evans, L. 2001. Causal influence of car mass and size on driver fatality risk. American Journal of Public Health, 91(7), 1076-1081.

Evans, L. 2004. How to make a car lighter and safer. Paper No. 2004-01-1172. Warrendale, PA: Society of Automotive Engineers.

Faerber, E. 2001. EEVC research in the field of improvement of crash compatibility between passenger cars. Proceedings of the 17th International Technical Conference on the Enhanced Safety of Vehicles, paper number 444.

Available at http://www-nrd.nhtsa.dot.gov/pdf/nrd01/Esv/esv17/Proceed/search.pdf

Ford, H., with S. Crowther. 1922. My Life and Work. Kessinger Publishing (republished January 2003), 53.

German, J. 2006, Improving safety without impacting fuel economy. Honda Motor Company, October 4. 
German, J. 2007. Email Correspondence, May 18.

Greene, D.L. 2004. Why don't we just tax gasoline? IAEE/USAEE Meetings, Washington, DC, July 10.

Greene, D.L. 2006. Fuel economy policy and highway safety. Report prepared for the Hewlett Foundation, September 24.

Heavenrich, R. 2006. Light-duty automotive technology and fuel economy trends: 1975 through 2006. EPA420-R-06-011. Washington, DC: U.S. Environmental Protection Agency.

Insurance Institute for Highway Safety (IIHS). 2003. Faster travel and the price we pay. Status Report, 38(19), November 10.

Insurance Institute of Highway Safety (IIHS). 2007. Available at http://www.iihs.org/ratings/esc/esc.aspx

Intergovernmental Panel on Climate Change (IPCC). 2001. Key findings of working group II, February 19.

Jackson, James K. 2006. US trade deficit and the impact of rising oil prices. Congressional Research Service, November 14.

Kahane, C.J. 1997. Relationships between vehicle size and fatality risk in model year 1985-93 passenger cars and light trucks. NHTSA DOT HS 808 570. Washington, DC: National Highway Traffic Safety Administration, U.S. Department of Transportation.

Kahane, C.J. 2003. Vehicle weight, fatality risk and crash compatibility of model year 1991-99 passenger cars and light trucks. NHTSA DOT HS 809 662. Washington, DC: National Highway Traffic Safety Administration, U.S. Department of Transportation.

Kahane, C.J., 2004. Response to docket comments on NHTSA technical report "Vehicle weight, fatality risk and crash compatibility of model year 1991-99 passenger cars and light trucks." Submission to docket no.NHTSA-2003-16318. Washington, DC: National Highway Traffic Safety Administration, U.S. Department of Transportation.

Kebschull, S., et al. 2004. An analysis of the effects of SUV weight and length on SUV crashworthiness and compatibility using systems modelling and risk-benefit analysis. DRI-TR-04-04-2, US DOT Docket NHTSA-2003-16128-1452. Torrance, CA: Dynamic Research, Inc., July.

Lovins, A.B., Data, E.K., Bustnes, O.E., Koomey, J.G., and Glasgow, N.J. 2005. Winning the oil endgame. Snowmass, CO: Rocky Mountain Institute, 57-61.

Nash, Carl E. 2006. A market approach to motor vehicle safety . . . that also addresses tort reform. Product Safety E Liability Reporter, 34(8), 206-212.

National Highway Traffic Safety Administration (NHTSA). 2005. Motor vehicle crash data from FARS and GES, 2006.

National Research Council (NRC). 2002. Effectiveness and impact of corporate average fuel economy standards. Washington, DC: National Academy Press.

Newstead, S.V., Farmer, C.M., Narayan, S., and Cameron, M.H. 2003. US consumer crash test results and injury risk in policy-reported crashes. Traffic Injury Prevention, 4, 113-127.

Noland, R.B. 2004. Motor vehicle fuel efficiency and traffic fatalities. Energy Journal, 25(4).

Odgaard, Thomas, and Bogelund, Mette. 2007. Cost-benefit assessment and prioritization of vehicle safety technologies. Norway: Department for Economics and Financial Analysis, COWI, Trafikdage pa Aalborg Universitet, January 30. 
O'Neill, B. 1998. The physics of car crashes and the role of vehicle size and weight in occupant protection. Physical Medicine and Rebabilitation: State of the Art Reviews, 12(1). Philadelphia, PA: Hanley \& Belfus, Inc.

O’Neill, B., Joksch, H., and Haddon, W. 1974. Empirical relationships between car size, car weight and crash injuries in car-to-car crashes. Proceedings of the 5th International Technical Conference on Experimental Safety Vehicles, London, June 4-7, 362-368.

Patel, D., Ross, M., Compton, C., and Wenzel, T. 2006. Intrusion and the aggressivity of light duty trucks in side impact crashes. Presentation at 2nd International Expert Symposium on Accident Research, Hanover, Germany, September 1-2.

Prasad, P., 2007. Email Correspondence, May 31.

Ross, Marc, Patel, Deena, and Wenzel, Tom. 2006. Vehicle design and the physics of traffic safety. Physics Today, 59, 49-54.

Runge, Jeffrey. 2003. North American International Auto Show, Michigan, January.

Shahed, S.M. 2006. An analysis of assisted turbocharging with light hybrid powertrain. SAE Technical Paper Series, 2006-01-0019. Warrendale, PA: Society of Automotive Engineers.

South Coast Air Quality Management District (SCAQMD). 2000. Multiple air toxics exposure study in the South Coast Air Basin (MATES II), March.

Transportation Research Board (TRB). 2005. Lives saved by the federal motor vehicle safety standards and other vehicle safety technologies, 1960-2002. Washington, DC, January 25.

U.S. Environmental Protection Agency (US EPA) and U.S. Department of Energy (US DOE). 2007. 2007 fuel economy guide. Available at www.fueleconomy.gov

Union of Concerned Scientists (UCS). 2003. Building a better SUV: A blueprint for saving lives, money, and gasoline, September.

Union of Concerned Scientists (UCS). 2006. Optimizing fuel economy and safety to avoid tradeoffs. Hewlett Foundation Workshop, October 4.

Van Auken, R.M., and Zellner, J.W. 2005a. An assessment of the effects of vebicle weight and size on fatality risk in 1985 to 1998 model year passenger cars and 1985 to 1997 model year light trucks and vans. SAE Technical Paper Series, 2005-01-1354. Warrendale, PA: Society of Automotive Engineers.

Van Auken, R.M., and Zellner, J.W. 2005b. Supplemental results on the independent effects of curb weight, wheelbase, and track on fatality risk in 1985-1998 model year passenger cars and 1985-1997 model year LTVs. DRI-TR-05-01. U.S. DOT Docket NHTSA-2003-16318-17. Torrance, CA: Dynamic Research, Inc., May.

Wenzel, T.P., and Ross, M. 2005. The effects of vehicle model and driver behavior on risk." Accident Analysis and Prevention, 37, 479-494.

Wenzel, T.P, and Ross, M. 2006. Increasing the fuel economy and safety of new light-duty vehicles. Paper presented at the Hewlett Foundation's Workshop, "Simultaneously Improving Vehicle Safety and Fuel Economy Through Improvements in Vehicle Design and Materials, Washington, DC, October 4.

Report design: Elizabeth DiPalma Design 
The International Council on Clean Transportation

1250 I St., Suite 350

Washington, DC 20005

(202) 347-8932

http://www.theicct.org/

\author{
The William and Flora Hewlett Foundation \\ 2121 Sand Hill Road \\ Menlo Park, CA 94025 \\ (650) 234-4500 \\ http://www.hewlett.org
}

